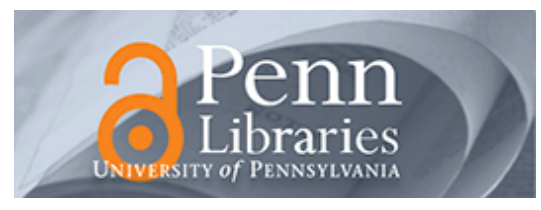

University of Pennsylvania

ScholarlyCommons

Business Economics and Public Policy Papers

Wharton Faculty Research

$10-2011$

\title{
Private Monitoring and Communication in Cartels: Explaining Recent Collusive Practices
}

Joseph E. Harrington Jr

University of Pennsylvania

Andrzej Skrzypacz

Follow this and additional works at: https://repository.upenn.edu/bepp_papers

Part of the Business Administration, Management, and Operations Commons, Business Intelligence Commons, Economics Commons, Organizational Behavior and Theory Commons, and the Public Affairs, Public Policy and Public Administration Commons

\section{Recommended Citation}

Harrington, J. E., \& Skrzypacz, A. (2011). Private Monitoring and Communication in Cartels: Explaining Recent Collusive Practices. American Economic Review, 101 (6), 2425-2449. http://dx.doi.org/10.1257/ aer.101.6.2425

This paper is posted at ScholarlyCommons. https://repository.upenn.edu/bepp_papers/148

For more information, please contact repository@pobox.upenn.edu. 


\title{
Private Monitoring and Communication in Cartels: Explaining Recent Collusive Practices
}

\author{
Abstract \\ Motivated by recent cartel practices, a stable collusive agreement is characterized when firms' prices and \\ quantities are private information. Conditions are derived whereby an equilibrium exists in which firms \\ truthfully report their sales and then make transfers within the cartel based on these reports. The \\ properties of this equilibrium fit well with the cartel agreements in a number of markets including citric \\ acid, lysine, and vitamins.

\section{Disciplines} \\ Business | Business Administration, Management, and Operations | Business Intelligence | Economics | \\ Organizational Behavior and Theory | Public Affairs, Public Policy and Public Administration
}




\title{
Private Monitoring and Communication in Cartels: Explaining Recent Collusive Practices ${ }^{\text {It }}$
}

\author{
By Joseph E. HARrington AND ANDRZEJ SKRZYPACZ
}

\begin{abstract}
Motivated by recent cartel practices, a stable collusive agreement is characterized when firms' prices and quantities are private information. Conditions are derived whereby an equilibrium exists in which firms truthfully report their sales and then make transfers within the cartel based on these reports. The properties of this equilibrium fit well with the cartel agreements in a number of markets including citric acid, lysine, and vitamins. (JEL D43, D82, K21, L12, L61, L65)
\end{abstract}

Cartel enforcement has been an active area of antitrust policy in recent years in the United States, European Union, and many other parts of the world. The objective of this paper is to use some of what we've recently learned about collusive practices to better understand how and when cartels are able to operate effectively. 1 Towards that end, we identify common features of recent cartel agreements and construct an equilibrium of a repeated game with private monitoring that matches some key features of those agreements. We begin by offering a few brief case studies to describe a common environment faced by cartels and then describe the common way in which they've structured the collusive mechanism. This serves to lay out the facts that we seek to explain.

Lysine is added to livestock feed to develop body tissue in pigs and poultry. In the early 1990s, the five major lysine producers formed a global cartel which lasted until mid-1995. Though two of the firms-Ajinomoto and Sewon-recommended colluding through the allocation of exclusive geographic markets, Archer Daniel Midlands (ADM) pushed for and succeeded in having accepted a sales quota scheme whereby each firm was entitled to a certain level of output. The agreed-upon allocation for 1992 for the global and European markets is shown in Table 1. ${ }^{2}$ Cartel

\footnotetext{
* Harrington: Department of Economics, Johns Hopkins University, Baltimore, MD 21218-2685 (e-mail: joe. harrington@jhu.edu); Skrzypacz: Graduate School of Business, Stanford University, Stanford, CA 94305-5015 (e-mail: andy@gsb.stanford.edu). We appreciate the comments of three anonymous referees, Susan Athey, Jimmy Chan, William Fuchs, Dino Gerardi, Johannes Hörner, and participants at the Bates White Antitrust Conference (2008), UBC Summer Conference on Industrial Organization (2008), University of East Anglia-Centre for Competition Policy Conference (2009), and Duke-Northwestern-Texas IO Theory Conference (2009), and at seminars at Cornell University, the European Commission, Michigan State University, and Yale University. The support of the National Science Foundation is acknowledged by the first author under grant SES-0516943 and the second author under SES-0721090.

${ }^{\dagger}$ To view additional materials, visit the article page at http://www.aeaweb.org/articles.php?doi=10.1257/aer.101.6.2425.

${ }^{1}$ Information about recent cartels can be found in John M. Connor (2001), Margaret C. Levenstein and Valerie Y. Suslow (2004), Harrington (2006), and Levenstein and Suslow (2006).

${ }^{2}$ Unless otherwise noted, all ensuing facts are from European Commission decisions and can be found in Harrington (2006).
} 
TAble 1-Lysine Market Allocation (1992, tons)

\begin{tabular}{lcr}
\hline \hline Company & Global & Europe \\
\hline Ajinomoto & 73,500 & 34,000 \\
Archer Daniels Midland & 48,000 & 5,000 \\
Kyowa & 37,000 & 8,000 \\
Sewon & 20,500 & 13,500 \\
Cheil & 6,000 & 5,000 \\
\hline
\end{tabular}

Source: Official Journal of the European Union, L 152/24, 7.6.2001, Case COMP/36.545/F3.

members also coordinated on price. For example, in a cartel meeting in July 1992, it was agreed to raise the price to $\$ 1.05 / \mathrm{lb}$ by September 30,1992, and to raise it again to $\$ 1.20 /$ lb by December $30,1992$.

To monitor compliance, Kanji Mimoto of Ajinomoto was assigned the task of preparing monthly "scorecards" for the cartel. Each company telephoned or mailed their sales volumes to Mimoto, who then prepared a spreadsheet that was distributed at the quarterly meetings of the cartel. To promote compliance, "guaranteed buy-ins" were used: a company that sold more than its quota had to buy output from producers who were below quota.

There were isolated reports of cartel members underreporting their sales in order to avoid the punishment associated with guaranteed buy-ins. For example, Cheil claimed to the European Commission that it provided "misleading" sales information to the other companies, while Ajinomoto hid 3,500 tons of lysine from the cartel's auditors. An internal memo read: "Hide 1,000 tons in Thailand internal business." Nevertheless, the collusive agreement was largely successful.

Citric acid is primarily used in the food and beverage industry, but is also an ingredient in household cleaning products, pharmaceuticals, and cosmetics, as well as having some industrial uses. From early 1991 to mid-1995, the five largest producers of citric acid operated a cartel. At the time, they made up about 60 percent of global production and 67 percent of production in the European Union. A sales quota scheme was established in terms of market shares. Reported in Table 2, these market shares were based on the average of the previous three years' sales.

As with the lysine cartel, the market allocation was monitored through the reporting of sales. On a monthly basis, each company reported its sales to an executive of Hoffmann LaRoche. The data were then assembled and reported back to the members by telephone. To provide some external validity, the reported sales were checked by independent Swiss auditors. Enforcement was through a "buy-back system" whereby a company that exceeded its assigned quota in any one year was obliged to purchase product from the companies with sales below their quota in the following year. For example, at a cartel meeting in November 1991, it was determined that Haarmann and Reimer needed to buy 7,000 tons of citric acid from ADM and it seemed the purchase was later made. In terms of efficacy, actual production by each member adhered very closely to the cartel's planned production.

There are a number of properties common to the citric acid and lysine cartels that we would like to highlight. First note that demand in these markets came from

\footnotetext{
${ }^{3}$ Official Journal of the European Communities, L 152/24, 7.6.2001, Case COMP/36.545/F3-Amino Acids, Decision of 7 June 2000; paragraph 77.
} 
Table 2-Citric Acid Market Allocation (1991)

\begin{tabular}{lc}
\hline \hline Company & Market share (percent) \\
\hline Haarman and Reimer & 32.0 \\
Archer Daniels Midland & 26.3 \\
Jungbunzlauer & 23.0 \\
Hoffman LaRoche & 13.7 \\
Cerestar Bioproducts & 5.0 \\
\hline
\end{tabular}

Source: Official Journal of the European Union, L 239/18, 6.9.2002, Case COMP/E-1/36.604.

industrial buyers, with price typically being set bilaterally between a seller and a buyer. This meant that price, along with firm sales, were not public information. Second, the collusive agreement was in terms of an allocation of sales, and not just coordination on a common price. Third, the collusive agreement was monitored by comparing sales to the agreed-upon quotas. Fourth, monitoring used self-reported sales which, on the whole, were not verifiable. Fifth, the collusive agreement was (at least partly) enforced through a transfer scheme whereby firms that reported sales above their quota effectively made a payment (through interfirm purchases) to those firms that reported sales below their quota.

These properties are not unique to the citric acid and lysine cartels. The setting of sales quotas with monitoring in terms of reported sales was also a practice deployed by cartels in the markets for carbonless paper, choline chloride, copper plumbing tubes, graphite electrodes, plasterboard, vitamins, and zinc phosphate. For example, from the European Commission decision on the vitamins cartel: "The purpose of the quarterly meetings was to monitor achieved market shares against quota and to adjust sales levels to comply with the agreed allocations." "\#

The accuracy of reported sales was established ex post for the carbonless paper cartel: "Comparison of these figures with information on real sales figures confirms that the sales volume information exchanged at the meeting was accurate." ${ }^{5}$ Finally, the use of a transfer scheme based upon reported sales was also documented for cartels in choline chloride, organic peroxides, sodium gluconate, sorbates, vitamins, and zinc phosphate. For example, for the choline chloride cartel "... it was understood that Akzo Nobel and UCB could claim 35 percent and 28 percent respectively, while BASF would have 15 percent. The principle was accepted that compensation should be provided if these shares were exceeded."

In fact, these collusive practices are not a recent phenomenon, as they were present in the International Steel Agreement of 1926. Sales quotas were fixed according to Articles 3 and 4 and resulted in the allocation in Table 3. Article 5 specified that monitoring would be in terms of sales: "Every month each country's actual net production of crude steel during that month shall be ascertained, in relation to the figures indicated by the quotas." And in Articles 6 and 7, penalties were specified in terms of monetary transfers between firms: "If the quarterly production of a country exceeds the quota which was fixed for it, that country shall pay in respect

\footnotetext{
${ }^{4}$ Quoting from the European Commission decision for the vitamin B2 cartel (Harrington 2006, p. 47).

${ }^{5}$ Quoting from the European Commission decision for the carbonless paper cartel (Harrington 2006, p. 51).

${ }^{6}$ Quoting from the European Commission decision for the choline chloride cartel (Harrington 2006, p. 58).
} 
Table 3-International Steel Agreement (1926)

\begin{tabular}{lc}
\hline \hline Country & Allocated market share (percent) \\
\hline Germany & 40.45 \\
France & 31.89 \\
Belgium & 12.57 \\
Luxemburg & 8.55 \\
Saar Territory & 6.54 \\
\hline
\end{tabular}

Source: Alfred Plummer (1938).

of each ton in excess a fine of 4 dollars, which shall accrue to the common fund.... If the production of any country has been below the quota allotted to it, that country shall receive in compensation from the common fund the sum of two dollars per ton short." Thus, the collusive practices observed in more recent years have been in use for at least 80 years.

What the preceding summary of cartels reveals is that, when faced with colluding in an environment in which prices and quantities are not easily observed, firms responded with a similar design to their collusive agreement. Toward better understanding hard-core cartels, the primary objective of our research is to explain how these well-documented collusive practices were effective in sustaining collusion. What prevents firms from undercutting the collusive price and then underreporting their sales? How can cartel members be induced to truthfully report their sales when higher sales reports require providing compensation to other members? We show that, if market demand is not too volatile, an equilibrium exists in which firms truthfully report their sales and set collusive prices, with asymmetric punishments that could be implemented using guaranteed buy-ins or buy-backs. Thus, observed collusive practices fit quite well within the equilibrium framework.

Our informational setting - in which the history of actions is private information and players engage in costless communication-is not new to the repeated game literature, and various folk theorems have been derived. ${ }^{7}$ While the oligopoly game we examine is not a member of the class of games considered in those papers, the more crucial distinction lies in objectives. The focus of previous work on private monitoring is to characterize the set of equilibrium payoffs. In contrast, we want to explain observed collusive agreements by constructing an empirically valid equilibrium that sustains collusion when firms do not publicly observe prices or quantities.

The model is described in Section I and, as a benchmark, the static Nash equilibrium is characterized in Section II. The main result is in Section III, where we show that, under certain demand conditions, collusion can be sustained when prices and sales are private information using a strategy profile consistent with observed cartel practices. Section IV discusses some limitations to the analysis and poses several open questions to be addressed in future research. Section V concludes.

\footnotetext{
${ }^{7}$ Research includes Olivier Compte (1998), Michihiro Kandori and Hitoshi Matsushima (1998), Masaki Aoyagi (2002), Bingyong Zheng (2008), and Ichiro Obara (2009). For reviews of some of this literature, see Kandori (2002) and George J. Mailath and Larry Samuelson (2006). A separate line of related work explores contracting when a principal privately observes workers' performance; see Jonathan Levin (2003), W. Bentley MacLeod (2003), William Fuchs (2007), and a discussion in the online Appendix.
} 


\section{Model}

There are $n \geq 2$ firms which, in each period of an infinite horizon setting, simultaneously choose price from a compact set, after which each firm's sales are stochastically determined. (As is typical, it is assumed that a firm supplies to meet demand.) The stochastic realization for period $t$ is composed of total demand, $m^{t}$, and an allocation of that demand described by a vector of firms' quantities, $q^{t}$, both of which are i.i.d. over time. Market demand is integer-valued and lies in the finite set $\Gamma \equiv\{\underline{m}, \underline{m}+1, \ldots, \bar{m}-1, \bar{m}\}$, where $0 \leq \underline{m}<\bar{m}$ and $\bar{m}$ is finite. Let $\rho: \Gamma \rightarrow[0,1]$ be a probability function, where $\rho(m)$ is the probability that the total demand is $m$. Define

$$
\mu \equiv \sum_{m=\underline{m}}^{\bar{m}} \rho(m) m
$$

as the average market sales. Note that market demand does not depend on firms' prices. While firm demand will be sensitive to price, market demand is perfectly inelastic. ${ }^{8}$ Firms have a common constant marginal cost of $c$.

An individual firm's demand has support $\{0,1, \ldots, \bar{q}\}$, where $\bar{q}$ is finite and, of course, $\bar{q} \leq \bar{m}$. (Assuming the lower bound to firm sales/quantity is zero is not important. $)$ Let $\Psi(\underline{\mathbf{q}} ; m, \underline{\mathbf{p}})$ denote the probability that the quantity vector is $\underline{\mathbf{q}}=\left\{q_{1}, \ldots, q_{n}\right\}$, given price vector $\underline{\mathbf{p}}=\left\{p_{1}, \ldots, p_{n}\right\}$ and market demand $m$. To focus on symmetric equilibria, we assume that the probability distribution $\Psi$ of how the market demand is split is symmetric across the firms (i.e., it is invariant to permutations of firm identities):

$\mathbf{A 1} \Psi(\underline{\mathbf{q}} ; m, \underline{\mathbf{p}})=\Psi(\omega(\underline{\mathbf{q}} ; i, j) ; m, \omega(\underline{\mathbf{p}} ; i, j)) \quad \forall i, j, \forall(\underline{\mathbf{q}}, \underline{\mathbf{p}})$, where $\omega(\underline{\mathbf{q}} ; i, j)$ is the vector $\underline{\mathbf{q}}$ when elements $i$ and $j$ are exchanged.

Next let $\psi_{i}(q ; m, \mathbf{p})$ be the probability function on firm $i$ 's sales given total demand $m$ and the price vector $\mathbf{p}\left(\psi_{i}\right.$ is a marginal distribution of $\left.\Psi\right)$. Let $\sigma_{i}(\cdot ; q, \underline{\mathbf{p}})$ denote firm $i$ 's beliefs on total sales given it sells $q$ units and the price vector $\underline{\mathbf{p}}$. By Bayes's rule,

$$
\sigma_{i}(m ; q, \underline{\mathbf{p}})=\frac{\rho(m) \psi_{i}(q ; m, \underline{\mathbf{p}})}{\sum_{m^{\prime}=\underline{m}}^{\bar{m}} \rho\left(m^{\prime}\right) \psi_{i}\left(q ; m^{\prime}, \underline{\mathbf{p}}\right)} .
$$

Two conditions are required of $\sigma_{i}$ (which implicitly places conditions on $\rho$ and $\psi_{i}$ ). A2 specifies that a firm always assigns positive probability to demand equalling its maximum value, which is weaker than assuming $\sigma_{i}$ has full support. A3 assumes

\footnotetext{
${ }^{8}$ One can interpret the assumption that demand is inelastic not literally, but rather that there exists a choke price $\bar{p}$ such that for $p \leq \bar{p}$ the demand is inelastic and for $p>\bar{p}$ it is zero, where $\bar{p}$ represents the price of an alternative input or the price at an alternative source in case of geographically concentrated cartels. With this interpretation our results hold for prices below $\bar{p}$. While we make this assumption for purposes of tractability, it is plausible for many of the markets mentioned in the introduction, including choline chloride, citric acid, and vitamins. We elaborate on this point in Section IV.
} 
that the higher a firm's quantity, the more weight the firm attaches to total demand being higher: 9

$\mathbf{A 2} \sigma_{i}(\bar{m} ; q, \underline{\mathbf{p}})>0, \forall q, \forall \underline{\mathbf{p}}$.

A3 If $q^{\prime}>q^{\prime \prime}$, then $\sigma_{i}\left(\cdot ; q^{\prime}, \underline{\mathbf{p}}\right)$ first-order stochastically dominates $(\mathrm{FOSD}) \sigma_{i}\left(\cdot ; q^{\prime \prime}, \underline{\mathbf{p}}\right)$, $\forall q^{\prime}, q^{\prime \prime}, \forall \underline{\mathbf{p}}$.

The setting is an infinitely repeated game in which, in each period, firms choose price and then stochastic demand is realized. Let $\delta$ be the common discount factor and assume a firm acts to maximize the expected present value of its profit stream. Each firm's price and realized sales are private information. This structure is augmented by allowing firms to make public messages and conduct monetary transfers. The sequence of decisions and events is described below.

Stage 1 (price): Each firm chooses a nonnegative price.

Stage 2 (sales): With prices being private information, each firm learns its sales.

Sales 3 (report): With prices and sales being private information, firms simultaneously submit publicly observed costless messages from the set $\{\varnothing, 0,1, \ldots, \bar{q}\}$, where $\varnothing$ means providing no message. (A message is to be interpreted as a sales report). 10

Sales 4 (transfer): With prices and quantities being private information and reports being public information, each firm makes a publicly observed nonnegative payment which is divided equally among the other $n-1$ firms.

To place this model in perspective, the problem we are tackling is one of collusion with imperfect monitoring, which originated with George J. Stigler (1964) and was first formally treated in a game-theoretic setting by Edward J. Green and Robert H. Porter (1984). With the latter treatment, which has become the standard approach, firms choose quantities in a homogeneous goods industry with price being determined by those quantities and an unobserved demand shock. Firms' quantities are private information, while price is a public signal. In contrast, we assume both prices and quantities are private information in the context of a price-setting game. Most closely related is an earlier work by Harrington and Skrzypacz (2007), from which the current paper differs in three ways. First, firms' quantities are private information, which is at the heart of the problem we're addressing here. Second, market demand is stochastic, which is empirically compelling and required to make the problem interesting (this is explained in Section III). Third, each firm sets a single

\footnotetext{
${ }^{9} \mathrm{~A} 2$ and A3 hold, for example, when $\Psi$ is derived from a binomial distribution; that is, each of $m$ customers independently chooses from which firm to buy. A proof is available from the authors upon request.

${ }^{10}$ This specification modestly departs from actual cartel practices. For example, the citric acid cartel had Haarman and Reimer, ADM, Jungbunzlauer, and Cerestar simultaneously submit sales reports to Hoffman LaRoche, after which Hoffman LaRoche added its sales report and then disseminated all of the reports. This meant that Hoffman LaRoche submitted its sales report after learning the reports of the other four cartel members.
} 
price for all customers instead of a customer-specific price. This third assumption appears to be more for convenience, and we argue later that our results are likely to be robust to it.

Finally, let us mention some other work that explores collusion for similar environments. Robert C. Marshall and Leslie M. Marx (2008) also consider a setting in which prices and sales are private information but assume that any deviation in price is perfectly identified from firms' market shares. In contrast, we assume market shares are subject to shocks and thus there is imperfect monitoring, which is central to our equilibrium theory of collusive behavior. In comparison to Susan Athey and Kyle Bagwell (2001, 2008), in our model prices are private and firms report sales, while in their model actions are public but firms have private cost shocks that they report to the cartel. The similarity is that in both models firms compete in prices; the difference is in the source of the incentive problem. Athey and Bagwell $(2001,2008)$ need to create incentives for firms to truthfully share cost information in order to achieve greater joint profits by giving more market share to the firm with lower cost, while in our setting there need to be incentives for firms to truthfully share sales information in order to monitor compliance, thereby providing proper pricing incentives. Finally, a recent paper by Jimmy Chan and Wenzhang Zhang (2009) builds on our work by designing a novel and quite different collusive scheme.

\section{Static Nash Equilibrium}

Before considering the infinitely repeated setting, let's establish the noncollusive benchmark. Firm $i$ 's expected profit is

$$
\pi_{i}\left(p_{1}, \ldots, p_{n}\right)=\sum_{m=\underline{m}}^{\bar{m}} \rho(m)\left(p_{i}-c\right) \sum_{q=0}^{m} q \psi_{i}(q ; m, \underline{\mathbf{p}}) .
$$

Let $p^{N}(c)$ denote a symmetric Nash equilibrium:

$$
p^{N}(c) \in \arg \max _{p} \sum_{m=\underline{m}}^{\bar{m}} \rho(m)(p-c) \sum_{q=0}^{m} q \psi_{i}\left(q ; m, p, p^{N}, \ldots, p^{N}\right) .
$$

We will assume the demand structure allows for a symmetric Nash equilibrium for the static game, as specified in Assumption A4:

A4 The static game with $\operatorname{cost} c$ has, $\forall c \geq 0$, a symmetric Nash equilibrium price $p^{N}(c)$ that is increasing, continuous, and unbounded in $c$.

A sufficient condition for A4 to hold is that: (i) $\psi_{i}(q ; m, \underline{\mathbf{p}})$ depends only on pairwise price differences, which can be derived from a model of consumer choice with quasi-linear preferences in money; (ii) the first-order condition (FOC) is sufficient to characterize equilibrium for any cost; and (iii) $\psi_{i}(q ; m, \mathbf{p})$ is interior for any equilibrium prices. Indeed, as we show in the online Appendix, under these conditions a firm's equilibrium price equals its cost plus a constant, which satisfies A4. 


\section{Sustaining Collusive Outcomes}

Before moving on to the main result, let us first note that sustaining collusion is trivial when market demand is common knowledge, either because it is fixed or is stochastic but observed. Suppose it is common knowledge that market demand is $m^{\prime}$. If firm $i$ expects the other firms to make truthful sales reports, then firm $i$ knows that if its report is inaccurate total reported sales will differ from $m^{\prime}$. Although the other firms will not know who delivered a misleading sales report, it will be common knowledge among them that someone did. Thus, if there is a (common) punishment when total reported sales differ from $m^{\prime}$, firms can be induced to report truthfully if they are sufficiently patient. Once firms are motivated to report truthfully, the collusive scheme presented in Harrington and Skrzypacz (2007) can sustain collusion. 11 We then assume market demand is stochastic and unobserved.

Consider a symmetric strategy profile in which there are two phases: collusive and noncollusive. Suppose the industry is in the collusive phase in period $t$. During the price stage, the strategy has a firm set the collusive price. After firm $i$ learns its sales - denoted $q_{i}^{t}$-it then truthfully reports those sales. If all firms have submitted reports, then firm $i$ pays $z r_{i}^{t}$ to the other firms, where $r_{i}^{t}$ was the firm's sales report in the previous stage (in equilibrium, $r_{i}^{t}=q_{i}^{t}$ ). If all firms make their payments, then there is a public randomization device which determines whether the industry remains in the collusive phase or shifts to the noncollusive phase. The probability function for shifting to the noncollusive phase is denoted $\phi:\{0,1,2, \ldots\} \rightarrow[0,1]$; its argument is the sum of firms' sales reports. If a firm does not submit a report or failed to make the appropriate payment, then the industry shifts to the noncollusive phase. Once an industry is in the noncollusive phase, firms price according to the static Nash equilibrium, don't make reports, and don't make payments. We refer to this strategy profile as the lysine strategy profile and it is summarized below for firm $i$ :

- In the price stage:

— if in the collusive phase then price at $\hat{p}$;

- if in the noncollusive phase then price at $p^{N}$.

- In the report stage:

— if in the collusive phase then report $r_{i}^{t}=q_{i}^{t}$;

— if in the noncollusive phase then do not report.

- In the transfer stage:

— if in the collusive phase,

${ }^{11}$ This collusive scheme is described in the proof of Theorem 1. 
* and all firms reported, where $\left(r_{1}^{t}, \ldots, r_{n}^{t}\right)$ is the vector of reports, then make a payment of $r_{i}^{t} z$ (which is then equally divided among the other $n-1$ firms);

* and one or more firms did not report then make a zero payment.

— if in the noncollusive phase then make a zero payment.

- In the transition stage (public randomization device):

— if in the collusive phase,

* all firms reported and $x_{j}^{t}=r_{j}^{t} z \forall j$ (where $x_{j}^{t}$ is firm $j$ 's payment), then firms remain in the collusive phase with probability $1-\phi\left(\sum_{j=1}^{n} r_{j}^{t}\right)$ and shift to the noncollusive phase with probability $\phi\left(\sum_{j=1}^{n} r_{j}^{t}\right)$;

* otherwise, firms go to the noncollusive phase with probability one.

— if in the noncollusive phase then firms remain in the noncollusive phase with probability one.

The lysine strategy profile fits reasonably well with recent collusive practices in markets such as citric acid, lysine, and vitamins. For when firms' prices and quantities are private information - an appropriate feature of those markets - the cartel monitors the agreement by having firms report their sales, and then punish for reported overproduction by having monetary transfers move from overproducers to underproducers. In practice, these transfers were performed through interfirm sales which, as long as price exceeds cost, act like monetary transfers. (Unfortunately, we lack documentation regarding the price of interfirm sales.) A desirable feature of performing transfers in this manner is that they did not create suspicion since interfirm sales were a common competitive feature of these markets. The one feature of the lysine strategy profile that is not expressly referred to in the documentation of these cases is the conditions under which the cartel collapses. The lysine strategy profile specifies that the probability of collusion stopping depends on firms' sales reports, as well as whether the requisite payments were made. In practice, evidence is scarce that such contingencies are expressly discussed by cartel members; even the 1926 International Steel Agreement did not specify in the contract what would happen if a firm did not pay the required $\$ 4$ for each ton above its quota. Our working assumption is that implicit in any collusive agreement is that egregious behavior-not making the requisite payment, incredible sales reports, and the like-risks causing the cartel to collapse.

Theorem 1 provides sufficient conditions whereby the lysine strategy profile is a semipublic perfect equilibrium, which is a sequential equilibrium satisfying certain properties. Defined and used in Compte (1998), this solution concept requires that equilibrium actions depend only on the public history, and messages depend only on 
the public history and the most recent private history. ${ }^{12}$ In our setting, this means that prices and payments depend only on the public history of past reports and payments, while a firm's report depends only on the public history of reports and payments and the private information composed of the firm's price and sales in the current period. 13

Given a condition on the volatility of market demand, Theorem 1 shows that collusive outcomes are sustainable when firms are sufficiently patient. More specifically, if firms are sufficiently patient and condition (1) in Theorem 1 holds, then a collusive price $\hat{p}$ is supportable using the lysine strategy profile and, in addition, the probability of transiting to the noncollusive phase is arbitrarily small. In interpreting (1), recall that $\bar{m}$ is the maximal value of market demand and $\mu$ is average market demand. As $p^{N^{-1}}(\cdot)$ is the inverse of the static Nash equilibrium price function, then $p^{N^{-1}}(\hat{p})$ is the marginal cost for which the static Nash equilibrium price equals $\hat{p}$. Since $\hat{p}>p^{N}(c)$, then $p^{N^{-1}}(\hat{p})-c>0$. If $\rho(\cdot)$ puts sufficient mass on maximal demand so that average demand is close to maximal demand, then (1) will hold. ${ }^{14}$ Thus, Theorem 1 shows that if demand is not "too stochastic"-in the restricted sense that average demand is not too much lower than maximal demand-then collusion can be sustained when firms are sufficiently patient. The proof of Theorem 1 is in the Appendix.

THEOREM 1: For any $\hat{p}>p^{N}$ and $\varepsilon>0$, there exists $\underline{\delta}<1$ such that if $\delta>\underline{\delta}$ and

$$
\frac{\mu}{\bar{m}-\mu}>\frac{(n-1)\left[p^{N^{-1}}(\hat{p})-c\right]}{\hat{p}-p^{N}},
$$

then the lysine strategy profile is a semipublic perfect equilibrium and

$$
\max \{\phi(m): \underline{m} \leq m \leq \bar{m}\}<\varepsilon
$$

If we impose the additional structure on demand to deliver $p^{N}(c)=c+$ const (namely, that consumers have quasi-linear preferences in money), then (1) takes a more easy-to-interpret form:

$$
\frac{\mu}{\bar{m}-\mu}>n-1
$$

In that case, Theorem 1 can be restated as:

COROLLARY 2: Suppose $p^{N}(c)=c+$ const. If $\mu /(\bar{m}-\mu)>n-1$, then for any $\hat{p}>p^{N}$ and $\varepsilon>0$, there exists $\underline{\delta}<1$ such that if $\delta>\underline{\delta}$ then the lysine strategy profile is a semipublic perfect equilibrium with $\max \{\phi(m): \underline{m} \leq m \leq \bar{m}\}<\varepsilon$.

\footnotetext{
${ }^{12}$ To be more exact, messages depend on the private history since the last period in which messages were informative. Compte (1998) considered equilibria in which there was delay in the sending of informative messages. In the equilibrium we characterize, there is no delay.

${ }^{13}$ Agreements consisting of reports and transfers after every period are also a feature of relational contracts as in Levin (2003) where, as here, tractability is enhanced by using monetary transfers in place of continuation payoffs to provide incentives. For a further comparative discussion of our paper and Levin (2003), see the online Appendix Section 2.1.

${ }^{14}$ Given that the left-hand side of $(1)$ is unbounded as $\mu \rightarrow \bar{m}$ and the right-hand side is bounded, then (1) is satisfied.
} 
Given firms truthfully report their sales, the mechanism used to sustain a collusive price is the same as in Harrington and Skrzypacz (2007). For each unit that a firm sells (and reports), it makes a payment of $z$ to the other cartel members. Thus, when a firm sells a unit rather than have the unit sold by another firm, it ends up paying $z$ rather than receiving $z /(n-1)$, so the net effect is $(n /(n-1)) z$. This means that a firm's effective marginal cost is $c+(n /(n-1)) z$. As a firm's price affects only its current profit and its net transfer-but not its future payoff-the equilibrium (collusive) price is simply the static Nash equilibrium price when each firm faces a marginal cost of $c+(n /(n-1)) z$. A higher collusive price can then be sustained by setting a higher per unit transfer.

The preceding argument rests on a firm truthfully reporting its sales, and there is clearly an incentive to underreport, since doing so reduces the required payment to other firms. The collusive mechanism offsets this temptation to underreport by making it more likely that the cartel breaks down when the aggregate sales report is smaller. ${ }^{15}$ Specifically, we use the following specification in the proof of Theorem 1 :

$$
\phi(m)= \begin{cases}\beta(\bar{m}-m)(1-\delta) & \text { if } m \leq \bar{m} \\ (1-\delta)^{\omega} & \text { if } m>\bar{m}\end{cases}
$$

where $\omega \in(0,1)$ and 16

$$
\beta \geq \frac{(n-1)\left[p^{N^{-1}}(\hat{p})-c\right]}{\delta\left\{\mu\left(\hat{p}-p^{N}(c)\right)-(n-1)\left[p^{N^{-1}}(\hat{p})-c\right](\bar{m}-\mu)\right\}} .
$$

This probability of cartel breakdown (see Figure 1) is decreasing and linear for equilibrium values of the aggregate sales report. Thus, underreporting is discouraged because a lower sales report is more likely to cause collusion to end. In counteracting the incentive to underreport, however, one could create an incentive to overreport; a firm reports higher sales and makes a higher payment in order to reduce the likelihood of cartel collapse. Here, we use the fact that an overreport results in reported market sales taking on, with positive probability, a nonequilibrium value (that is, in excess of maximal demand $\bar{m}$ ). While the probability of a price war is decreasing in total reported sales for equilibrium values of total demand, the probability of a price war is higher when total reported sales exceeds maximal demand (at least, when $\delta \rightarrow 1$ ). Firms then do not want to overreport sales either. ${ }^{17}$ Finally, as a positive probability of collusion ending is needed to induce firms to truthfully report their sales, there is an inefficiency. While the probability of cartel breakdown goes to zero as $\delta \rightarrow 1$, the inefficiency is bounded above zero.

\footnotetext{
${ }^{15}$ While we have specified a punishment of infinite reversion to the stage game Nash equilibrium, this collusive mechanism will also work with finite reversion, in which case there are periodic price wars.

${ }^{16}$ Note that the lower bound on $\beta$ in (4) is bounded with respect to $\delta$, which means we can ensure $\phi(m)<1$ as $\delta \rightarrow 1$.

${ }^{17}$ In some situations, overreporting may be deterred by requiring invoices for reported sales or a customer list which could then be contacted. There is no analogous verification process to detect underreporting because a firm could withhold invoices or deliver a subset of its true customer list. In other words, evidence can be provided to prove that a sale was made, but it is not possible to provide evidence that a sale wasn't made. This discussion suggests that the challenge is to provide incentives to discourage underreporting.
} 


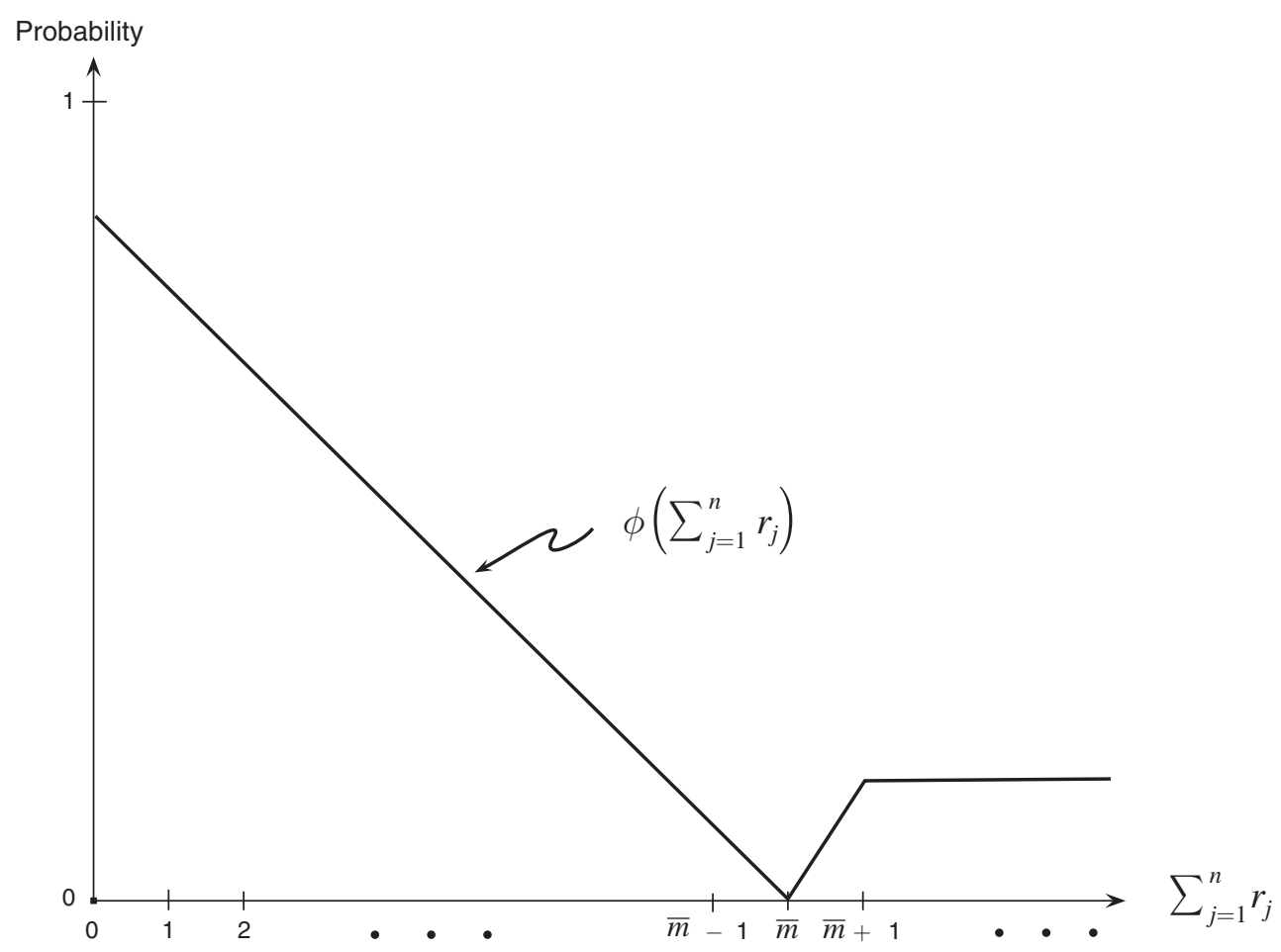

Figure 1

To explain the source of the restriction in (1), we need to examine the following incentive compatibility constraint (ICC):

$$
\delta\left(V-V^{N}\right) \sum_{m=\underline{m}}^{\bar{m}} \sigma_{1}(m \mid q, \underline{\mathbf{p}})[\phi(m-1)-\phi(m)] \geq z .
$$

This ICC ensures it is better to report truthfully than to underreport by one unit. Underreporting by one unit reduces firm 1's payment to other firms by $z$, which is the right-hand side of $(5)$. The left-hand side is the expected reduction in the future payoff from reporting $q-1$ rather than $q$. The probability of cartel breakdown is increased by $\phi(m-1)-\phi(m)$ (when the market demand realization is $m$ ) and the foregone future payoff due to cartel breakdown is $V-V^{N}$, where $V$ is the collusive value and $V^{N}$ is the noncollusive value. In the proof of Theorem 1, it is shown that (5) is the binding ICC and is the source of (1) $\underline{18}$

To show how (1) implies (5), first note that

$$
\hat{p}=p^{N}\left(c+\left(\frac{n}{n-1}\right) z\right) \Leftrightarrow z=\left(\frac{n-1}{n}\right)\left[p^{N^{-1}}(\hat{p})-c\right]
$$

\footnotetext{
${ }^{18}$ It is established in the proof of Theorem 1 that, when $\phi$ is weakly convex, if it is not optimal to underreport by one unit, then it is not optimal to underreport by any amount. Also, given (3), (5) is the same regardless of $(q, \mathbf{p})$.
} 
in which case (1) is equivalent to

$$
\frac{\left[\hat{p}-p^{N}(c)\right](\mu / n)}{z}>\bar{m}-\mu
$$

Since

$$
V-V^{N}=\frac{\left[\hat{p}-p^{N}(c)\right](\mu / n)}{1-\delta+\delta \sum_{m=\underline{m}}^{\bar{m}} \rho(m) \phi(m)},
$$

the foregone loss from cartel breakdown is increasing in the collusive price $\hat{p}$, and is decreasing in the probability of cartel breakdown, $\sum_{m=\underline{m}}^{\bar{m}} \rho(m) \phi(m)$. As $\hat{p}$ is increasing in the per unit transfer $z$, this argues for a higher value of $z$ in order to raise the average gain in profit from maintaining collusion, $\left[\hat{p}-p^{N}(c)\right](\mu / n)$. At the same time, $z$ is the savings in the payment that a firm has to make when it underreports by one unit, in which case higher $z$ also increases the incentive to underreport. What is then needed is that $\left[\hat{p}-p^{N}(c)\right](\mu / n)$ is large enough relative to $z$, which is what (6) requires. ${ }^{19}$ A second key factor determining the size of $V-V^{N}$ is the probability of cartel breakdown, which is the expression

$$
\text { (8) } \sum_{m=\underline{m}}^{\bar{m}} \rho(m) \phi(m)=\sum_{m=\underline{m}}^{\bar{m}} \rho(m) \beta(\bar{m}-m)(1-\delta)=\beta(\bar{m}-\mu)(1-\delta) \text {. }
$$

For $V-V^{N}$ to be large, (8) needs to be small and, therefore, (5) holds. Hence, $\bar{m}-\mu$ must be small enough, as expressed in (6). In sum, sustaining collusion requires that: (i) the rise in the collusive price from a per unit transfer is sufficiently large relative to the size of the per unit transfer; and (ii) the likelihood of low demand is sufficiently small so that cartel breakdown is not too likely.

To get some sense of the plausibility of the demand restriction in Theorem 1, consider when the static Nash equilibrium price is $c+$ const, so the restriction takes the form in (2). Next suppose market sales is uniformly distributed on $\{\underline{m}, \ldots, \bar{m}\}$. Since then $\mu=(\underline{m}+\bar{m}) / 2,(2)$ is

$$
\frac{(\underline{m}+\bar{m}) / 2}{\bar{m}-(\underline{m}+\bar{m}) / 2}>n-1 \Rightarrow \frac{n}{n-2}>\frac{\bar{m}}{\underline{m}} .
$$

With uniformly distributed market demand, the condition is that the ratio of the upper bound to the lower bound of market sales is less than $n /(n-2)$. If $n=2$, this condition is satisfied as long as $\underline{m}>0$. If $n=3$ (4), then it is satisfied if the upper bound of market demand is no more than thrice (twice) the lower bound. For many markets in which cartels have been observed, these bounds are quite reasonable. Most cartels involve commodities and the demand for such goods is unlikely to be volatile in terms of unanticipated variation. While demand may significantly change because in (6).

${ }^{19}$ When $p^{N}(c)=c+$ const, as in Corollary 2, then $\hat{p}-p^{N}(c)=(n /(n-1)) z$ and, therefore, $z$ cancels out 
of the business cycle or trends in growth, that variation is largely anticipated and can be controlled when it comes to monitoring. The fluctuation in market demand that we are modelling is unanticipated variation, which is probably not large. All this suggests that it is quite plausible that the demand condition required for the lysine strategy profile to be an equilibrium will hold in markets prone to cartels.

Finally, let us show that, as the discount factor goes to one, supracompetitive profits can be sustained using the lysine strategy profile. Rescaling by $1-\delta$, the normalized supracompetitive payoff is $(1-\delta)\left(V-V^{N}\right)$. Substituting the minimum value of $\beta$ from (4), we derive

$$
(1-\delta)\left(V-V^{N}\right)=(1 / n)\left[\mu\left(\hat{p}-p^{N}(c)\right)-n z(\bar{m}-\mu)\right] .
$$

Thus, $(1-\delta)\left(V-V^{M}\right)>0$ if and only if

$$
\mu\left[\hat{p}-p^{N}(c)\right]-n z(\bar{m}-\mu)>0,
$$

which holds by (6). In sum, we have shown that, when prices and quantities are private information, firms can effectively sustain collusion using the type of practices observed by recent cartels in the markets for citric acid, lysine, and vitamins. 20

\section{Limitations of the Analysis and Future Research Directions}

In this section we discuss some limitations to our model and equilibrium with the purpose of assessing the robustness of our results and identifying areas for future research.

- An assumption in our model is that market demand, while stochastic, does not depend on firms' prices; a firm's price influences only its market share. How restrictive is this assumption and how robust are our results to it?

The key implication of assuming that market demand is independent of price is that total sales is not a signal of firms' prices. If demand is price-elastic there may exist equilibria that rely on it and achieve higher profits than the lysine strategy profile, but we conjecture that the lysine strategy profile will still be an equilibrium. While the equilibrium condition on price is more complicated (as now a firm's price affects market size) and will result in different prices, it will still be determined by the static Nash equilibrium for a modified stage game.

It is also relevant to note that the independence of transfers to total sales is consistent with collusive practice, as cartels generally monitored compliance using market

\footnotetext{
${ }^{20}$ Let us return to the assumption that firms must set uniform prices. A possible implication from allowing firms to set customer-specific prices (that is, a different price for each unit of market demand) is that a firm could cheat by lowering prices for only a subset of customers which, in principle, could make detection more difficult. This deviation option does not, however, affect the lysine strategy profile because prices are set according to a static Nash equilibrium; there is no incentive to deviate in price. The binding incentive compatibility constraints are for reports and transfers, and those are unaffected by customer-specific pricing. In fact, Harrington and Skrzypacz (2007) explicitly allowed for consumer-specific prices. They consider the same model as here-except that sales are public information - and the same type of strategy profile on prices and transfers. Results were shown to be the same for uniform and customer-specific prices.
} 
shares, not total sales (though a possible exception is when quotas were in terms of volume rather than market share, in which case total sales indirectly mattered). One of the reasons market sales was generally not used by the cartels to monitor prices might be that the market demand was, in fact, highly inelastic, in which case market sales was relatively uninformative. This seems plausible for many of the markets we described in the introduction. Consider the markets for lysine and citric acid. These products are being purchased by other firms as inputs; for example, lysine is mixed with animal feed in the food processing industry. As they make up a very small fraction of the unit cost of the purchaser's product, their demand is likely to be insensitive to price for a wide range of prices. Of course, the cartel members could set price high enough to induce a nonnegligible fall in market demand, but the size of the price increase required to make that happen may be of such a magnitude to create suspicions among buyers that the input suppliers are colluding. Hence, over the relevant range of prices, market demand is highly inelastic. An important caveat, however, is when the cartel is not all-inclusive. If a nontrivial set of firms is outside of the cartel (such as the Chinese manufacturers in the market for vitamin $\mathrm{C}$ ), then total cartel supply will be sensitive to a cartel member's price, even if market demand is perfectly inelastic, in which case total cartel supply can be informative as to cartel members' prices.

- For the lysine strategy profile to be an equilibrium, it was required that average demand is sufficiently close to maximal demand (condition (1)). Can collusion be sustained without this demand restriction being satisfied?

It may be possible to construct collusive equilibria even if demand condition (1) does not hold, though it is likely to involve a strategy distinct from the lysine strategy. Pertinent to this issue, two examples are presented in the online Appendix. In the first example, the lower bound to market demand, $\underline{m}$, is strictly positive and even; sufficient probability mass is assigned to $m=\underline{m}$; and the upper bound to market demand, $\bar{m}$, is high enough to violate (1). For when there is a duopoly, a collusive scheme is constructed with each firm having a quota of $\underline{m} / 2$, which means that a firm that reports sales smaller than its quota is given a side payment by the other firm proportional to the shortfall. The way the scheme curtails incentives to underreport sales is by using punishments off the equilibrium path when the sum of reports falls short of $\underline{m}$. Its efficiency then relies critically on the lower bound to total sales. In comparison with the lysine strategy, it does not need value burning on the equilibrium path and it does not rely on knowing $\bar{m}$, as punishments are not required when reports are too high. A final interesting feature is that it is based on quantity quotas rather than market share quotas.

The second example we present in the online Appendix involves the simple case when $m \in\{0,1,2\}$. A mechanism design approach delivers an upper bound on payoffs for the set of symmetric semipublic equilibria in which firms report sales without delay. We further show that this upper bound is implementable by equilibria in the dynamic game when players are sufficiently patient. Condition (1) is found to be tight for semipublic perfect equilibria without delay. Namely, if $\rho(0)$ is sufficiently high—so that (1) is violated-then no collusion can be sustained (with semipublic 
equilibria without delay); and if $\rho(2)$ is sufficiently high — so that (1) is satisfiedcollusion is possible.

Overall, our intuition is that in any collusive scheme the cartel has to resolve two incentive problems: underpricing and underreporting. To resolve underpricing we think that it is necessary to involve transfers as a function of reported sales, at least if $\psi_{i}$ is smooth (that intuition is based on the results in Harrington and Skrzypacz 2007). Since transfers depending on reported sales create incentives to misreport sales, our conjecture is that to prevent underreporting it is necessary in any collusive scheme to trigger punishment if the sum of reports is too small. In some cases (like in our first example above), such punishments can be restricted to off the equilbrium path; in other cases (as with our second example), they need to happen on the equilibrium path. ${ }^{21]}$ If that value destruction happens too often, collusion will generate too little value and sustaining high prices will not be possible. Hence, for some probability distributions on market demand, it may not be possible to sustain any collusion with semipublic equilibria and reports every period (as our second example in the online Appendix illustrates).

- Our model assumed that the only source of information on other firms' sales were the self-reported numbers by those firms. Some cartels, however, received external verification of sales from outside auditors. How does the availability of other sources of information on sales affect the structure of equilibrium?

In some cartels, firms did attempt to independently verify sales. The most extreme form of verification was to hire independent auditors to investigate the accuracy of sales reported by a firm to the cartel (auditors from Switzerland were popular). While such independent verification did occur, it was not typical. For example, we are unaware of any documented usage of an independent auditor in a domestic US cartel. It is important to recognize that, even when outside auditors are used, they provide a noisy signal of sales because a cartel member can attempt to hide sales from auditors. The use of auditors and the strategic hiding of sales were both present in the lysine cartel (see Harrington 2006). An area for future research is to characterize the properties of equilibrium when cartel members make sales reports and receive noisy signals of sales. As the binding incentive compatibility constraints for the lysine strategy profile are those for the reporting stage (rather than the price and transfer stages), loosening those constraints through additional information on sales could produce more effective collusion. That much seems obvious. What is less obvious is the form of the collusive mechanism when there are both self-reported sales and independent signals of sales.

- In our equilibrium, the frequency of sales realizations, sales reports, and transfers were identical. It was quite common, however, for a cartel to have sales reports that were less frequent than sales realizations and for transfers to be less frequent than sales reports. Is the lysine strategy profile robust to this modification? Why would a cartel not choose to have the timing of sales realizations, sales reports, and transfers coincide?

\footnotetext{
${ }^{21}$ When $m \in\{0,1\}$, one can show that this conjecture is correct for any (even asymmetric) pure strategy semipublic equilibrium with reports every period.
} 
We believe our equilibrium is robust to these modifications. First, consider delay in making transfers. When it chooses its price or sales report, a firm may now have accumulated transfers (from sales reports since the last transfers were made). But since it expects to pay those transfers in the future, its incentive for setting price and truthfully reporting sales in the current period is influenced only by the change in the accumulated transfer wrought by the current price and sales report. Both of those incentive compatibility constraints are then altered only by the fact that the transfer needs to be discounted. Finally, the incentive compatibility constraint for transfers is assured of holding because that involves perfect monitoring, and thus is satisfied as long as firms are sufficiently patient, regardless of how often transfers are made.

Next, turn to when sales reports are less frequent. Suppose that sales are realized each period but firms exchange sales report and make transfers every $\tau$ periods. It can be shown that Theorem 1 still holds, but where (1) is replaced with

$$
\frac{\mu}{\bar{m}-\mu}>\left(\frac{(n-1)\left[p^{N^{-1}}(\hat{p})-c\right]}{\hat{p}-p^{N}(c)}\right)\left(\frac{\delta^{\tau}-\delta^{\tau+1}}{\delta-\delta^{\tau+1}}\right) .
$$

With reports occurring every $\tau$ periods, the collusive value is different because collusion is assured for $\tau$ periods as a result of the public randomization device occurring only after reports are made. Price is still set according to a static Nash equilibrium condition, although it is complicated by the fact that transfers occur only every $\tau$ periods, which affects the virtual marginal cost that a firm faces.

While our equilibrium is robust to delayed sales reports and transfers, this leaves open the more important question of why firms did choose to delay sales reports and transfers. If larger transfers make detection by the antitrust authority more likely, then firms may want to intertemporally aggregate transfers on the hope that net transfers will be smaller. There is also a body of work that suggests that information delay can be useful for achieving more efficient equilibria—see, for example, Dilip Abreu, Paul Milgrom, and David Pearce (1991), Compte (1998), and Kandori and Matsushima (1998). In the online Appendix, we have an example in which, when the lower bound to market demand is zero, all equilibria involve value destruction (that is, a price war occurs with positive probability), and another example in which the lower bound to market demand is positive and there is an equilibrium without value destruction. If value destruction can be avoided when the lower bound to market sales is high enough, then this could be a rationale for delaying the reporting of sales. More attention needs to be given to the role of delay in our setting.

\section{Concluding Remarks}

As it has been understood for a long time, monitoring of a collusive agreement is essential to its success. Only if firms can expect noncompliance to be observed and punished will cartel members abide by the agreement to maintain high prices and limit supply. In spite of the critical role of monitoring, there are many well-documented episodes of successful collusion in markets for which there is limited public information to use for the purposes of monitoring compliance. In environments for which prices and sales are private information, it was frequently observed that collusion involved a similar set of practices: firms self-report sales and conduct inter-firm transfers based 
on those reports; specifically, firms with high sales compensate those firms with low sales. The main contribution of this paper is to show how those practices can result in successful collusion in this informationally scarce environment. To induce firms to set a collusive price, the equilibrium strategy has a firm make a payment to the other firms for each unit that it reports having sold. To induce truthful reporting of sales, the probability of cartel breakdown - reversion to a stage game Nash equilibrium - is specified to be higher when total reported market sales are lower. Thus, a firm that underreports its sales realizes a benefit by having to make a lower payment to the other firms, but also incurs a cost by increasing the probability that collusion breaks down. In equilibrium, the cost of the increased likelihood of cartel breakdown exceeds the benefit from reduced interfirm payments, so that a firm finds it optimal to truthfully report its sales.

When the market involves intermediate goods-so that customers are industrial buyers and thus price is private information between a buyer and a seller-our theory suggests what antitrust authorities should look for in terms of collusive practices and outcomes. First, they should look for firms exchanging sales reports. While this can occur in secret, it can also occur through a trade association. Second, interfirm sales or other forms of compensation, as the use of asymmetric punishments is essential to effective collusion (a point originally made by Harrington and Skrzypacz 2007). Third, periodic price wars, as it is the possible threat of a price war that induces firms to truthfully report their sales. Thus, information exchange, interfirm transfers, and periodic price wars all add up to potential indicators of collusion.

\section{ApPendix: Proof of TheOREM 1}

In proving that the lysine strategy profile is a semipublic perfect equilibrium, we need to establish: (i) given any history of reports and payments, the prescribed price is optimal; (ii) given any history of reports and payments and, for the current period, a firm's price and sales, the prescribed report is optimal; and (iii) given any history of reports and payments (including the sales reports of firms in the current period), the prescribed payment is optimal. We will tackle them in that sequence with the bulk of the analysis concerning the incentive compatibility of sales reports, which is step (ii). When the public history has one or more firms not submitting reports or one or more firms not making payments, the optimality of behavior is obvious because the industry is in the noncollusive phase. Our attention will then focus on public histories on the equilibrium path, which means firms are in the collusive phase and all firms submitted reports and made the appropriate payments.

By symmetry, let us restrict the analysis to firm 1. Given a generic price vector $\underline{\mathbf{p}}$ and the anticipation that truthful reports will be submitted and transfers will be made, firm 1's payoff at the price stage is

$$
\begin{aligned}
\sum_{m=\underline{m}}^{\bar{m}} \rho(m) \sum_{q=0}^{m} \psi_{1}(q ; m, \underline{\mathbf{p}})\{ & {\left[\left(p_{1}-c\right) q+z\left(\frac{m-q}{n-1}\right)-z q\right] } \\
& \left.+\phi(m) \delta V^{N}+(1-\phi(m)) \delta V\right\} .
\end{aligned}
$$

$V$ is the value when in the collusive phase and $V^{N}$ is the value when in the noncollusive phase. Note that a firm with sales $q$ expects to pay $z q$, while receiving an 
equal share of the payments made by the other $n-1$ firms which equal $z(m-q)$. Simplifying this expression, we derive

$$
\begin{aligned}
& \sum_{m=\underline{m}}^{\bar{m}} \rho(m) \sum_{q=0}^{m} \psi_{1}(q ; m, \underline{\mathbf{p}})\left(p_{1}-c-\left(\frac{n}{n-1}\right) z\right) q \\
+ & \sum_{m=\underline{m}}^{\bar{m}} \rho(m)\left[\phi(m) \delta V^{N}+(1-\phi(m)) \delta V\right]+z\left(\frac{\mu}{n-1}\right) .
\end{aligned}
$$

Thus, if the collusive price is $\hat{p}$ then the ICC at the price stage is

$$
\begin{aligned}
& \sum_{m=\underline{m}}^{\bar{m}} \rho(m) \sum_{q=0}^{m} \psi_{1}(q ; m, \hat{p}, \ldots, \hat{p})\left(\hat{p}-c-\left(\frac{n}{n-1}\right) z\right) q \\
\geq & \sum_{m=\underline{m}}^{\bar{m}} \rho(m) \sum_{q=0}^{m} \psi_{1}\left(q ; m, p_{1}, \hat{p}, \ldots, \hat{p}\right)\left(p_{1}-c-\left(\frac{n}{n-1}\right) z\right) q, \forall p_{1} .
\end{aligned}
$$

(10) is satisfied if and only if $\hat{p}=p^{N}(c+(n /(n-1)) z)$; that is, $\hat{p}$ is the static Nash equilibrium when unit cost is $c+(n /(n-1)) z$. For any $z$, we will then assume $\hat{p}=p^{N}(c+(n /(n-1)) z)$. Since $p^{N}(c+(n /(n-1)) z)$ is continuously increasing and unbounded in $z$ by A4, then for any $p>p^{N}$ there exists $z>0$ such that $p=p^{N}(c+(n /(n-1)) z)$.

Taking account of the fact that transfers average out to zero, expected collusive profit is

$$
\hat{\pi}(z) \equiv\left[p^{N}\left(c+\left(\frac{n}{n-1}\right) z\right)-c\right]\left(\frac{\mu}{n}\right)
$$

The collusive value is recursively defined by

$$
V=\hat{\pi}(z)+\sum_{m=\underline{m}}^{\bar{m}} \rho(m)\left[\phi(m) \delta V^{N}+(1-\phi(m)) \delta V\right] .
$$

The incremental gain from being in the collusive phase is

$$
V-V^{N}=\hat{\pi}(z)+\sum_{m=\underline{m}}^{\bar{m}} \rho(m)\left[\phi(m) \delta V^{N}+(1-\phi(m)) \delta V\right]-\hat{\pi}(0)-\delta V^{N} .
$$

Solving for $V-V^{N}$,

$$
\begin{aligned}
V-V^{N} & =\frac{\hat{\pi}(z)-\hat{\pi}(0)}{1-\delta+\delta \sum_{m=\underline{m}}^{\bar{m}} \rho(m) \phi(m)} \\
& =\frac{\left[p^{N}\left(c+\left(\frac{n}{n-1}\right) z\right)-p^{N}(c)\right](\mu / n)}{1-\delta+\delta \sum_{m=\underline{m}}^{\bar{m}} \rho(m) \phi(m)}
\end{aligned}
$$


This expression will be useful later in the proof.

The next step is to consider the optimality of a firm's strategy at the report stage. If in the collusive phase, then firm 1's beliefs put unit mass on other firms setting a price equal to $\hat{p}$. Firm 1's strategy is sequentially rational if the prescribed report is optimal given the other firms' current period price was $\hat{p}$, any arbitrary price for firm 1 , and any feasible level of realized sales for firm 1 , which is denoted $q_{1}$. 22

Recall that $\sigma_{1}\left(m \mid q_{1}, \underline{\mathbf{p}}\right)$ denotes firm 1's posterior beliefs on total demand conditional on its quantity and the price vector. Given the other firms are expected to provide a truthful report and make payments, firm 1's expected payoff from reporting $r_{1}$ (when its true sales is $q_{1}$ ) is

$$
\begin{array}{r}
W\left(r_{1} ; q_{1}, p_{1}\right)=\sum_{m=\underline{m}}^{\bar{m}} \sigma_{1}\left(m \mid q_{1}, \underline{\mathbf{p}}\right)\left\{\left[\left(p_{1}-c\right) q_{1}+\left(\frac{z}{n-1}\right)\left(m-q_{1}-(n-1) r_{1}\right)\right]\right. \\
\left.+\phi\left(m-q_{1}+r_{1}\right) \delta V^{N}+\left(1-\phi\left(m-q_{1}+r_{1}\right)\right) \delta V\right\} .
\end{array}
$$

The ICCs are

$$
W\left(q_{1} ; q_{1}, p_{1}\right) \geq W\left(r_{1} ; q_{1}, p_{1}\right) \forall r_{1} \in\{0,1, \ldots\}, \forall q_{1} \in\{0,1, \ldots \bar{q}\}, \forall p_{1}
$$

These ICCs ensure that, for any price set by firm 1 and any realized sales for firm 1 , firm 1 finds it optimal to truthfully report its sales. That statement presumes that firm 1 will make a payment of $z r_{1}$ regardless of what $r_{1}$ is, which we will later show to be optimal.

Our analysis proceeds through several steps. First, we derive a condition ensuring that it is not optimal to overreport sales; that is, $r_{1}=q_{1}$ is preferred to any $r_{1}>q_{1}$. In deriving a condition ensuring that it is not optimal to underreport-that is, $r_{1}=q_{1}$ is preferred to any $r_{1}<q_{1}$-we first derive a condition whereby if it is not optimal to underreport by one unit then it is not optimal to underreport by any amount. Then we derive a condition whereby if it is not optimal to underreport by one unit when $q_{1}=\bar{q}$ (so a firm's sales are at its maximum level), then it is not optimal to underreport by one unit when $q_{1}<\bar{q}$. We are then left with the property: if

$$
W\left(\bar{q} ; \bar{q}, p_{1}\right) \geq W\left(\bar{q}-1 ; \bar{q}, p_{1}\right), \forall p_{1},
$$

then all underreporting ICCs at the report stage are satisfied. Theorem 1 is derived by examining (13) as $\delta \rightarrow 1$. As we'll see, its satisfaction requires imposing certain properties on $\phi$.

\footnotetext{
${ }^{22}$ These conditions are sufficient but not necessary for semiperfect public equilibrium. It is possible there is a deviant price, after which reporting truthfully is not a best response, but that deviant price (along with the optimal report) is less profitable than setting the collusive price and reporting truthfully.

${ }^{23}$ Though semipublic perfect equilibrium requires only that the ICC holds when other firms are believed to price at $\hat{p}$, we will allow for any price vector in order to reduce the amount of notation.
} 
Let us start by deriving a condition that ensures that firm 1 prefers to provide a truthful sales report to overreporting sales. The ICC is

$$
\begin{aligned}
& \sum_{m=\underline{m}}^{\bar{m}} \sigma\left(m \mid q_{1}, \underline{\mathbf{p}}\right)\left\{\left[\left(p_{1}-c\right) q_{1}+\left(\frac{z}{n-1}\right)\left(m-n q_{1}\right)\right]\right. \\
& \left.+\phi(m) \delta V^{N}+(1-\phi(m)) \delta V\right\} \\
& \geq \sum_{m=\underline{m}}^{\bar{m}} \sigma\left(m \mid q_{1}, \underline{\mathbf{p}}\right)\left\{\left[\left(p_{1}-c\right) q_{1}+\left(\frac{z}{n-1}\right)\left(m-q_{1}-(n-1) r_{1}\right)\right]\right. \\
& \left.+\phi\left(m-q_{1}+r_{1}\right) \delta V^{N}+\left(1-\phi\left(m-q_{1}+r_{1}\right)\right) \delta V\right\}, \forall r_{1}>q_{1} .
\end{aligned}
$$

After some manipulations, we have

$$
\delta\left(V-V^{N}\right) \sum_{m=\underline{m}}^{\bar{m}} \sigma_{1}\left(m \mid q_{1}, \underline{\mathbf{p}}\right)\left[\phi\left(m-q_{1}+r_{1}\right)-\phi(m)\right] \geq z\left(q_{1}-r_{1}\right) .
$$

Interpreting (15), the right-hand side is the change in transfer from reporting $r_{1}$ instead of $q_{1}$. As $z>0$ and $r_{1}>q_{1}$, it is negative. The left-hand side is the expected change in the future payoff due to overreporting. It captures the impact of an overreport on the probability of transiting to the noncollusive phase. Equilibrium requires that the change in the expected future payoff is at least as great as the reduction in the current payoff from making a higher payment. As the right-hand side of (15) is negative, a sufficient condition for (15) to hold is then

$$
\delta\left(V-V^{N}\right) \sum_{m=\underline{m}}^{\bar{m}} \sigma_{1}\left(m \mid q_{1}, \underline{\mathbf{p}}\right)\left[\phi\left(m-q_{1}+r_{1}\right)-\phi(m)\right] \geq 0 .
$$

We will return to this condition later in the proof.

Next, consider the case of underreporting. The ICCs are

$$
\begin{gathered}
W\left(q_{1} ; q_{1}, p_{1}\right) \geq W\left(r_{1} ; q_{1}, p_{1}\right) \forall r_{1} \in\left\{0,1, \ldots, q_{1}-1\right\}, \\
\forall q_{1} \in\{0,1, \ldots \bar{q}\}, \forall p_{1} .
\end{gathered}
$$

Given $q_{1}$, reporting $r_{1}$ is preferred to $r_{1}-1$, where $r_{1} \leq q_{1}$, if and only if

$$
\begin{aligned}
& \text { (18) } \sum_{m=\underline{m}}^{\bar{m}} \sigma_{1}\left(m \mid q_{1}, \underline{\mathbf{p}}\right)\{[\left.\left(p_{1}-c\right) q_{1}+\left(\frac{z}{n-1}\right)\left(m-q_{1}-(n-1) r_{1}\right)\right] \\
&\left.+\phi\left(m-q_{1}+r_{1}\right) \delta V^{N}+\left(1-\phi\left(m-q_{1}+r_{1}\right)\right) \delta V\right\} \\
& \geq \sum_{m=\underline{m}} \sigma_{1}\left(m \mid q_{1}, \underline{\mathbf{p}}\right)\left\{\left[\left(p_{1}-c\right) q_{1}+\left(\frac{z}{n-1}\right)\left(m-q_{1}-(n-1)\left(r_{1}-1\right)\right)\right]\right. \\
&\left.+\phi\left(m-q_{1}+r_{1}-1\right) \delta V^{N}+\left(1-\phi\left(m-q_{1}+r_{1}-1\right)\right) \delta V\right\} .
\end{aligned}
$$


Performing some manipulations, we derive

$$
\begin{aligned}
\sum_{m=\underline{m}}^{\bar{m}} \sigma_{1}\left(m \mid q_{1}, \underline{\mathbf{p}}\right)[\phi(m & \left.\left.-q_{1}+r_{1}-1\right)-\phi\left(m-q_{1}+r_{1}\right)\right] \\
& \times \delta\left(V-V^{N}\right) \geq z .
\end{aligned}
$$

By underreporting by one unit, firm 1 reduces its payment by $z$, which is the righthand side of (19). The left-hand side is the expected change in the future payoff from underreporting.

What we want to show is that if (19) holds for $r_{1}=q_{1}$, then it holds $\forall r_{1}<q_{1}$, and this is true for $q_{1} \leq \bar{q}$. This is indeed the case if

$$
\phi\left(m-q_{1}+r_{1}-1\right)-\phi\left(m-q_{1}+r_{1}\right)
$$

is nonincreasing in $r_{1} \forall r_{1} \leq q_{1}, \forall q_{1} \leq \bar{q}$; or, equivalently, $\phi(m-1)-\phi(m)$ is nonincreasing in $m \forall m \leq \bar{m}$. From hereon, this property is assumed for $\phi$.

Having derived a sufficient condition on $\phi$ whereby if a firm doesn't want to underreport by one unit then it doesn't want to underreport by any amount, the next step is to derive a sufficient condition such that if it is not optimal to underreport by one unit given $q_{1}=q^{\prime}$, then it is not optimal to underreport by one unit given $q_{1}=q^{\prime}-1$. Using the explicit expressions, $W\left(q^{\prime} ; q^{\prime}, p_{1}\right) \geq W\left(q^{\prime}-1 ; q^{\prime}, p_{1}\right)$ takes the form

$$
\sum_{m=\underline{m}}^{\bar{m}} \sigma_{1}\left(m \mid q^{\prime}, \underline{\mathbf{p}}\right)[\phi(m-1)-\phi(m)] \geq \frac{z}{\delta\left(V-V^{N}\right)} .
$$

What we want to show is that if (20) holds, then (21) holds:

$$
\sum_{m=\underline{m}}^{\bar{m}} \sigma_{1}\left(m \mid q^{\prime}-1, \underline{\mathbf{p}}\right)[\phi(m-1)-\phi(m)] \geq \frac{z}{\delta\left(V-V^{N}\right)} .
$$

This is the case if and only if the left-hand side of (21) is at least as great as the lefthand side of $(20)$ :

$$
\begin{gathered}
\sum_{m=\underline{m}}^{\bar{m}} \sigma_{1}\left(m \mid q^{\prime}-1, \underline{\mathbf{p}}\right)[\phi(m-1)-\phi(m)] \\
\geq \sum_{m=\underline{m}}^{\bar{m}} \sigma_{1}\left(m \mid q^{\prime}, \underline{\mathbf{p}}\right)[\phi(m-1)-\phi(m)] .
\end{gathered}
$$

Since we've already assumed $\phi(m-1)-\phi(m)$ is nonincreasing in $m,(22)$ holds if $\sigma\left(\cdot \mid q^{\prime}, \underline{\mathbf{p}}\right)$ FOSD $\sigma\left(\cdot \mid q^{\prime}-1, \underline{\mathbf{p}}\right)$, which is true by A3.

To summarize, if $\phi(m-\overline{1})-\phi(m)$ is nonincreasing in $m \forall m \leq \bar{m}$, then (17) holds if and only if $W\left(\bar{q} ; \bar{q}, p_{1}\right) \geq W\left(\bar{q}-1 ; \bar{q}, p_{1}\right)$ or

$$
\delta\left(V-V^{N}\right) \sum_{m=\underline{m}}^{\bar{m}} \sigma_{1}(m \mid \bar{q}, \underline{\mathbf{p}})[\phi(m-1)-\phi(m)] \geq z .
$$


Substituting (11) into (23), we have

$$
\delta\left(\frac{\left[\hat{p}-p^{N}(c)\right](\mu / n)}{1-\delta+\delta \sum_{m=\underline{m}}^{\bar{m}} \rho(m) \phi(m)}\right) \sum_{m=\underline{m}}^{\bar{m}} \sigma_{1}(m \mid \bar{q}, \underline{\mathbf{p}})[\phi(m-1)-\phi(m)] \geq z .
$$

Summarizing the proof of Theorem 1 thus far, if the ICCs for the payment stage are satisfied (which is shown later), then the lysine strategy profile is a semipublic perfect equilibrium when: (i) $\hat{p}=p^{N}(c+(n /(n-1)) z)$; (ii) $\phi(m-1)-\phi(m)$ is nonincreasing in $m \forall m \leq \bar{m}$; (iii) (16) holds; and (iv) (24) holds. We now want to impose properties on $\phi$ so that (ii)-(iv) are satisfied as $\delta \rightarrow 1$.

Assume

$$
\phi(m)= \begin{cases}\beta(\bar{m}-m)(1-\delta) & \text { if } m \leq \bar{m} \\ (1-\delta)^{\omega} & \text { if } \bar{m}<m\end{cases}
$$

where $\beta>0$ and $\omega \in(0,1)$; see Figure 1 . With this specification, $\phi$ is decreasing in $m$ for $m \leq \bar{m}$, equals zero for $m=\bar{m}$, and is positive and constant for $m>\bar{m}$. Note that (ii) is then satisfied. Since $\lim _{\delta \rightarrow 1} \phi(m)=0$ for $m \leq \bar{m}$, then the equilibrium probability of a punishment goes to zero. As we will suppose $\delta \rightarrow 1, \phi(m)$ is assured of lying in $[0,1)$, as long as $\beta$ is bounded.

Inserting (25) into (24), we get

$$
\delta\left\{\frac{\left[\hat{p}-p^{N}(c)\right](\mu / n)}{1-\delta+\delta \sum_{m=\underline{m}}^{\bar{m}} \rho(m) \beta(\bar{m}-m)(1-\delta)}\right\} \sum_{m=\underline{m}}^{\bar{m}} \sigma_{1}(m \mid \bar{q}, \underline{\mathbf{p}}) \beta(1-\delta) \geq z .
$$

Simplifying and rearranging it, this ICC holds if and only if

$$
\beta\left[\mu\left(\hat{p}-p^{N}(c)\right)-n z(\bar{m}-\mu)\right] \geq \frac{n z}{\delta}
$$

If

$$
\mu\left(\hat{p}-p^{N}(c)\right)>n z(\bar{m}-\mu)
$$

then (26) is satisfied if $\beta$ is sufficiently large. Let us show that (27) is equivalent to $(1)$. Given $\hat{p}=p^{N}(c+(n /(n-1)) z)$, we can solve for the per unit transfer $z$ required to induce the collusive price $\hat{p}$ :

$$
p^{N}\left(c+\left(\frac{n}{n-1}\right) z\right)=\hat{p} \Leftrightarrow z=\left(\frac{n-1}{n}\right)\left[p^{N^{-1}}(\hat{p})-c\right]
$$

$p^{N^{-1}}$ exists by A4. Substituting (28) into (27) and rearranging gives us (1). In sum, if (1) holds and $\phi$ satisfies (25)-(26), then all of the underreporting ICCs hold. 
This leaves us just having to show (iii). This we will do by showing that (16) holds as $\delta \rightarrow 1$. Using (25) and assuming $r_{1}>q_{1}$, the left-hand side of (16) is

$$
\begin{aligned}
& \delta\left(V-V^{N}\right)\left\{\sum_{m=\underline{m}}^{\bar{m}-\left(r_{1}-q_{1}\right)} \sigma_{1}\left(m \mid q_{1}, \underline{\mathbf{p}}\right)\right. \\
& \times\left[\beta\left(\bar{m}-\left(m-q_{1}+r_{1}\right)\right)(1-\delta)-\beta(\bar{m}-m)(1-\delta)\right] \\
& \left.+\sum_{m=\bar{m}-\left(r_{1}-q_{1}\right)+1}^{\bar{m}} \sigma_{1}\left(m \mid q_{1}, \underline{\mathbf{p}}\right)\left[(1-\delta)^{\omega}-\beta(\bar{m}-m)(1-\delta)\right]\right\} \\
& =\delta\left(V-V^{N}\right)\left\{\sum_{m=\underline{m}}^{\bar{m}-\left(r_{1}-q_{1}\right)} \sigma_{1}\left(m \mid q_{1}, \underline{\mathbf{p}}\right)\left(q_{1}-r_{1}\right) \beta(1-\delta)\right. \\
& \left.+\sum_{m=\bar{m}-\left(r_{1}-q_{1}\right)+1}^{\sigma_{1}} \sigma_{1}\left(m \mid q_{1}, \underline{\mathbf{p}}\right)\left[(1-\delta)^{\omega}-\beta(\bar{m}-m)(1-\delta)\right]\right\} .
\end{aligned}
$$

Using (11) and (25), we substitute for $V-V^{N}$ in (29),

$$
\begin{aligned}
& =\delta \frac{\left[\hat{p}-p^{N}(c)\right](\mu / n)}{1-\delta+\delta \sum_{m=\underline{m}}^{\bar{m}} \rho(m) \beta(\bar{m}-m)(1-\delta)} \\
& \quad \times\left\{\sum_{m=\underline{m}}^{\bar{m}-\left(r_{1}-q_{1}\right)} \sigma_{1}\left(m \mid q_{1}, \underline{\mathbf{p}}\right)\left(q_{1}-r_{1}\right) \beta\right. \\
& \left.\quad+\sum_{m=\bar{m}-\left(r_{1}-q_{1}\right)+1}^{\bar{m}} \sigma_{1}\left(m \mid q_{1}, \underline{\mathbf{p}}\right)\left[(1-\delta)^{\omega-1}-\beta(\bar{m}-m)\right]\right\} .
\end{aligned}
$$

Letting $\delta \rightarrow 1$, the first term in $\{\cdot\}$ is bounded, while the second term is unbounded and positive, since $\omega-1<0$ implies $\lim _{\delta \rightarrow 1}(1-\delta)^{\omega-1}=+\infty$. (It is here where we use A2.) Hence, as $\delta \rightarrow 1$ then the expression in $\{\cdot\}$ is positive. Thus, (iii) holds as $\delta \rightarrow 1$.

The final step in proving the lysine strategy profile is a semipublic perfect equilibrium is to show that the prescribed behavior for the payment stage is optimal. First, note that reporting zero and following the equilibrium strategy (which entails a zero payment) is at least as good as any positive sales report and not making the corresponding payment; for the latter results in a punishment for sure while the former could have a punishment with probability less than one. Since we've already shown that reporting truthfully is weakly preferred to reporting zero and following the equilibrium strategy (obviously, the two reports are identical when realized sales is zero), it follows that a firm never finds it optimal to submit a report and then not make the corresponding payment. 24

\footnotetext{
${ }^{24}$ It can also be shown that, if firms are sufficiently patient and reports are bounded, it is always optimal to pay $z r$ after reporting $r$. Since monitoring is perfect, the usual argument works.
} 
In sum, if (1) holds, then, by choosing $\delta$ sufficiently close to one, the lysine strategy profile is a semipublic perfect equilibrium. Finally, for any $\varepsilon>0$, when $\delta$ is sufficiently close to one,

$$
\max \{\phi(m): \underline{m} \leq m \leq \bar{m}\}=\beta(\bar{m}-\underline{m})(1-\delta)<\varepsilon
$$

so the probability of a price war in any given period can be made arbitrarily small.

\section{REFERENCES}

Abreu, Dilip, Paul Milgrom, and David Pearce. 1991. "Information and Timing in Repeated Partnerships." Econometrica, 59(6): 1713-33.

-Aoyagi, Masaki. 2002. "Collusion in Dynamic Betrand Oligopoly with Correlated Private Signals and Communication.” Journal of Economic Theory, 102(1): 229-48.

Athey, Susan, and Kyle Bagwell. 2001. "Optimal Collusion with Private Information.” RAND Journal of Economics, 32(3): 428-65.

Athey, Susan, and Kyle Bagwell. 2008. "Collusion with Persistent Cost Shocks.” Econometrica, 76(3): 493-540.

Chan, Jimmy, and Wenzhang Zhang. 2009. "Price Wars, Side-Payments, and Collusion Enforcement." Unpublished.

-Compte, Olivier. 1998. "Communication in Repeated Games with Imperfect Private Monitoring." Econometrica, 66(3): 597-626.

Connor, John M. 2001. Global Price Fixing: Our Customers are the Enemy. Studies in Industrial Organization. Norwell, MA: Kluwer Academic Publishers.

-Fuchs, William. 2007. "Contracting with Repeated Moral Hazard and Private Evaluations." American Economic Review, 97(4): 1432-48.

-Green, Edward J., and Robert H. Porter. 1984. "Noncooperative Collusion under Imperfect Price Information." Econometrica, 52(1): 87-100.

-Harrington, Joseph E., Jr. 2006. "How Do Cartels Operate?" Foundations and Trends in Microeconomics, 2(1): 1-108.

Harrington, Joseph E., Jr., and Andrzej Skrzypacz. 2007. "Collusion under Monitoring of Sales." RAND Journal of Economics, 38(2): 314-31.

Kandori, Michihiro. 2002. "Introduction to Repeated Games with Private Monitoring." Journal of Economic Theory, 102(1): 1-15.

Kandori, Michihiro, and Hitoshi Matsushima. 1998. "Private Observation, Communication and Collusion." Econometrica, 66(3): 627-52.

Levenstein, Margaret, and Valerie Y. Suslow. 2004. "Contemporary International Cartels and Developing Countries: Economic Effects and Implications for Competition Policy.” Antitrust Law Journal, 71(3): 801-52.

Levenstein, Margaret C., and Valerie Y. Suslow. 2006. "What Determines Cartel Success?” Journal of Economic Literature, 44(1): 43-95.

Levin, Jonathan. 2003. "Relational Incentive Contracts." American Economic Review, 93(3): 835-57.

MacLeod, W. Bentley. 2003. "Optimal Contracting with Subjective Evaluation.” American Economic Review, 93(1): 216-40.

Mailath, George J., and Larry Samuelson. 2006. Repeated Games and Reputations: Long-Run Relationships. New York: Oxford University Press.

Marshall, Robert C., and Leslie M. Marx. 2008. "Explicit Collusion and Market Share Allocation." Unpublished.

-Obara, Ichiro. 2009. "Folk Theorem with Communication." Journal of Economic Theory, 144(1): 120-34.

Plummer, Alfred. 1938. International Combines in Modern Industry. New York: Pitman.

Stigler, George J. 1964. “A Theory of Oligopoly.” Journal of Political Economy, 72(2): 44-61.

Zheng, Bingyong. 2008. "Approximate Efficiency in Repeated Games with Correlated Private Signals." Games and Economic Behavior, 63(1): 406-16. 


\section{This article has been cited by:}

1. B. Douglas Bernheim, Erik Madsen. 2017. Price Cutting and Business Stealing in Imperfect Cartels. American Economic Review 107:2, 387-424. [Abstract] [View PDF article] [PDF with links]

2. Isaiah Andrews, Daniel Barron. 2016. The Allocation of Future Business: Dynamic Relational Contracts with Multiple Agents. American Economic Review 106:9, 2742-2759. [Abstract] [View PDF article] [PDF with links]

3. Yu Awaya, Vijay Krishna. 2016. On Communication and Collusion. American Economic Review 106:2, 285-315. [Abstract] [View PDF article] [PDF with links]

4. David Rahman. 2014. The Power of Communication. American Economic Review 104:11, 3737-3751. [Abstract] [View PDF article] [PDF with links]

5. Robert Clark, Jean-François Houde. 2013. Collusion with Asymmetric Retailers: Evidence from a Gasoline Price-Fixing Case. American Economic Journal: Microeconomics 5:3, 97-123. [Abstract] [View PDF article] [PDF with links] 